\title{
Impact on Family Functioning of Immediate Spica Casting for Pediatric Femur Fractures: An Ecological Study
}

Mininder S. Kocher, MD, MPH'1,2; Michelle L. Ciarlo, $\mathrm{MD}^{3}$; Aliya G. Feroe, MPH',2, Laura E. Dichtel, MD, MHS ; Jessica L. Traver, $M D^{5}$

${ }^{1}$ Department of Orthopaedic Surgery and Sports Medicine, Boston Children's Hospital, Boston, MA; ${ }^{2}$ Harvard Medical School, Boston, MA; ${ }^{3}$ Women's Health Center and Wellness, Wentworth-Douglass Hospital, Portsmouth, NH;

${ }^{4}$ Neuroendocrine Unit, Massachusetts General Hospital/Harvard Medical School, Boston, MA; ${ }^{5}$ Department of Orthopaedic Surgery, McGovern Medical School, University of Texas Health Science Center, Houston, TX

Correspondence to: Mininder S. Kocher MD, MPH, Boston Children's Hospital, 300 Longwood Ave., Boston, MA 02115, E-mail: Mininder.Kocher@childrens.harvard.edu

Received: January 3, 2022; Accepted: January 3, 2022; Published: February 1, 2022

DOI: 10.55275/JPOSNA-2022-0011

\begin{abstract}
:
Background: Treatment for femoral shaft fractures in children aged 6 months to 6 years old is closed reduction and immediate spica casting which places unique burdens and stresses on the family. The purpose of this study was to evaluate the impact on the family from an ecological perspective of immediate spica casting for femoral shaft fractures in children using appropriate validated family functioning questionnaires.

Methods: Families of 46 children aged 0.5 to 6.0 years old who were treated with immediate one-and-a-half leg spica casting for femur fracture were surveyed using the Impact on Family Score (IFS), the Feetham Family Functioning Survey (FFFS), and qualitative comments. The impact of spica cast treatment on family functioning was determined for multiple domains and compared between subgroups.

Results: Spica cast treatment had major impacts on the families of 46 children with a mean age of 2.9 years (range, 0.5-6.0 years) across multiple domains. The IFS demonstrated greater impact of spica cast treatment than treatment for children with major chronic illnesses. There was a greater impact on family for school age children (5-6 years old) compared to younger children (0.5-4 years old) for the overall IFS score, the general impact IFS domain, the disruption of family IFS domain, the coping IFS domain, and the overall FFFS discrepancy score. There was greater impact on family for children of working parent(s) compared to children with a parent at home for the overall IFS score, the
\end{abstract}


general impact IFS domain, the disruption of family IFS domain, the coping IFS domain, the financial impact IFS domain, and the overall FFFS discrepancy score. There was no correlation between duration of time spent in hip spica cast with either IFS or FFFS discrepancy score.

Conclusions: Spica cast treatment can have a major impact on family functioning, particularly in school age children and in families with working parents and each patient and family unit requires education and varying levels of support which may prepare them for the various ways their household dynamics could be affected throughout their child's treatment.

Level of Evidence: Level IV: Case series (no historical or control group)

\section{Key Concepts:}

- Pediatric femur fracture treatment with a spica cast has a significant impact on family dynamics.

- Education and support can help prepare them for these challenges.

\section{Introduction}

Femoral shaft fractures are the leading cause of musculoskeletal injury requiring pediatric hospitalization in the U.S. ${ }^{1}$ In children between 6 months and 6 years of age, femoral shaft fractures are traditionally treated with closed reduction and acute hip spica casting as recommended by the American Academy of Orthopaedic Surgeons (AAOS). ${ }^{2-14}$ In contrast, children over the age of 6 years have been increasingly treated by operative reduction and intramedullary stabilization. ${ }^{2,15}$ Acute hip spica casting is generally acceptable in terms of fracture healing, functional outcome, and risk of complications. . $^{6,7,16-24}$

However, spica casting of pediatric femur fractures can place unique burdens on the family unit related to the child's mobility, ability to attend school/preschool, and assistance with activities of daily living, psychosocial stress associated with caring for an injured child, and the socioeconomic impact of disrupted parental work schedules, family routines, and the cost of assistive equipment. ${ }^{8,16,18,19,22,23,25-27}$ In addition, families may receive little education and assistance in the care of a child in a spica cast. Few studies have formally assessed this family burden to understand the greater impact of immediate hip spica casting and the importance of these discussions with families at the time of initial treatment.

The purpose of this study was to apply an ecological framework to assess the overall impact of immediate spica casting for pediatric femoral shaft fractures on the family unit using validated family functioning questionnaires.

\section{Materials and Methods Cohort Development}

After obtaining institutional review board approval for this study, eligible patients were identified from a computerized database. Inclusion criteria included children who were treated with immediate spica casting for a unilateral femoral shaft fracture at a tertiary care children's hospital from 2000-2002 who were 6 months to 6 years of age at the time of treatment and within 1 year of treatment. Exclusion criteria included multiple fractures, fractures secondary to suspected or confirmed child abuse, nondiaphyseal fractures, open fractures, patients previously treated with a spica cast, patients treated with traction prior to spica casting, and patients with major coexisting diseases. Consent for the study was obtained from the parent through questionnaire. 


\section{Spica Casting Technique}

Immediate spica casting was performed in the operating room under general anesthesia. A waterproof liner was applied (Figure 1A). The patient was placed on a hip spica table. After closed reduction, a one-and-a-half leg spica cast was applied as previously described. ${ }^{21}$ The adequacy of reduction was assessed using intraoperative radiographic imaging. The involved leg was casted above the ankle and the uninvolved leg was casted above the knee. The patient was casted in the seating position (Figure 1B). The cast was trimmed with cut outs for the abdomen and the perineum (Figure 1C). Postoperatively, families received spica cast care teaching from inpatient nurses on the surgical ward. No formal instruction booklet or video was given. Patients were discharged from the hospital when deemed medically appropriate.

\section{Questionnaire Development and Distribution}

A specialized questionnaire (Supplemental Materials) was developed for this study, including both the Impact on Family Scale (IFS) and the Feetham Family Functioning Survey (FFFS). Qualitative family comments were solicited as well.

The IFS was developed in $1978^{28-33}$ and was utilized in 1980 in the Pediatric Ambulatory Care Treatment Study (PACTS). ${ }^{34}$ The IFS is a 27 -item score with Likert-scaling that measures the impact the child's health condition has on his/her family life. ${ }^{35,36}$ Questions

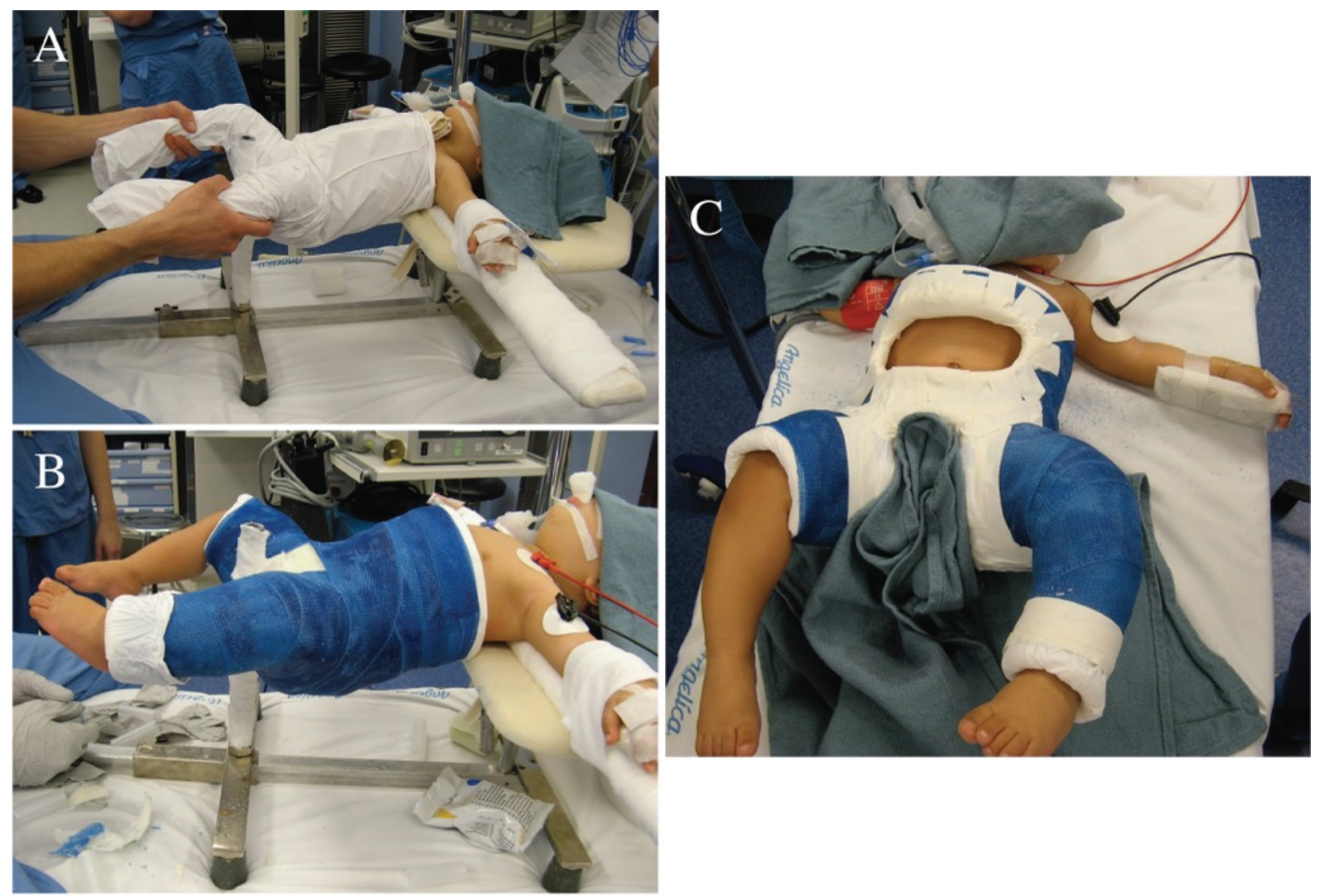

Figure 1. Immediate spica cast for pediatric femur fracture. (A) The patient was placed on a hip spica table, and a waterproof liner was applied under general anesthesia. (B) After closed reduction, a one-and-a-half spica cast was applied while the patient was in a seated position. The involved leg (left) was casted above the ankle, and the uninvolved leg (right) was casted above the knee. (C) The cast was trimmed with cut outs for the abdomen and the perineum. 
are asked regarding financial hardship, work changes, travel, social interactions with friends, social interactions with family, family dynamics, finding caregivers, stigmatization, opportunity costs, worry, fatigue, depression, marital or family strife, grades, and school impact. This survey is scored in four distinct areas: economic impact on family, social impact, familial impact, and personal strain/coping. Lower scores indicate a greater negative impact or disability on the family.

The FFFS was developed in the 1970s and it was first tested in 1976 to measure the functioning in families with infants born with myelodysplasia. ${ }^{37}$ Since then, the survey has been modified and used for a variety of medical conditions to measure the functioning of families through the use of discrepancy scores. ${ }^{38-45}$ The FFFS is a 25-item survey that follows the Porter design to facilitate self-administration. The FFFS measures the various parameters of family functioning based on individual perception. The survey utilizes the ecological framework for studying families and uses "stem questions" with three related responses. Questions are asked regarding how the medical condition affected discussions (with friends, relatives, and spouse), time (with spouse, neighbors, health professionals, children, housework, missed school, missed work, leisure activities), help (from spouse, relatives, friends), emotional support (from friends, relatives, spouse), problems with your child, and disagreements with spouse. From these stem domains, questions are asked regarding how much there actually was, how much there should have been, and how important this was to the family. The responses are graded on a 1 to 7 Likert scale. Absolute differences are calculated between how much of a given item there should have been compared to how much of that item there actually was. Differences represent aberrations from ideal ecological functioning. Higher discrepancy scores indicate greater dysfunction in family functioning.

The questionnaire was sent to families of eligible patients. For nonresponders, a second questionnaire was sent, and a follow-up phone call was made 3 months after sending the original questionnaire.

\section{Statistical Analysis}

Statistical analysis was performed using SPSS 15.0 (SPSS Inc., Chicago, IL U.S.). Overall mean scores and standard deviations were determined for overall scores and subscales. Normalcy of data was confirmed using the Kolmogorov-Smirnov test. Inter-group comparisons were made using the student t-test. Subgroup analyses by patient age compared children ages 5 to 6 years old to children ages 4 years and younger to identify differences between children attending and not yet attending school.

\section{Results}

\section{Cohort Characteristics}

There were 59 eligible patients. Questionnaires were sent to all 59 families and were returned by 46 families (response rate: 78\%). The mean age of the study patients was 2.9 years old (range, $0.5-6.0$ years). Of the 46 patients, 26 (57\%) were male. The mean time from fracture to completion of the survey was 0.7 years (range, 0.4 years- 1.0 years). The mean hospital stay was 1.2 days (range, $0-3$ days). The mean duration of casting was $5.3 \pm 1.18$ weeks (range, $3-8$ weeks). Twenty-seven $(59 \%)$ of the patients had working parents or a working single parent, while the other $19(41 \%)$ had a parent at home.

\section{Impact on Family Score}

The mean overall IFS score was 44.8 and was normally distributed ( $\mathrm{SD}=9.3$; range, 21-70; KolmogorovSmirnov $\mathrm{p}>0.05)$. For the general impact domain, the mean IFS subscore was 24.9 ( $\mathrm{SD}=5.6$; range, $11-36)$. For the financial impact domain, the mean IFS subscore was 6.3 ( $\mathrm{SD}=2.1$; range, $1-12$ ). For the disruption of family domain, the mean IFS subscore was 20.6 ( $\mathrm{SD}=4.6$; range, 10-32). For the coping domain, the mean IFS subscore was $5.6(\mathrm{SD}=1.7$; range, $1-12)$. There was no significant relationship between a child's duration of spica cast treatment and mean overall IFS score (Spearman correlation $\mathrm{r}=0.121, \mathrm{p}=0.430$ ).

The mean overall IFS score in these patients with pediatric femur fracture treated with immediate hip spica casting was significantly lower (signifying a greater 
impact on family) than the mean IFS score in patients in the original PACTS study, which was comprised of children with serious chronic medical conditions including asthma, diabetes, juvenile rheumatoid arthritis, and renal failure $(44.8 \pm 9.3$ vs. $48.0 \pm 8.2, \mathrm{p}=0.011) .{ }^{34}$

The school-aged children 5-6 years old $(n=12)$ had significantly lower scores - indicating a greater family impact - compared to the children 4 years old and younger $(n=34)$ in the general impact domain (mean $21.7 \pm 5.8$ vs. $26.1 \pm 5.3, \mathrm{p}=0.021)$, the disruption of family domain (mean $17.9 \pm 4.7$ vs. $21.5 \pm 4.4$, $\mathrm{p}=0.021$ ), and the coping domain (mean $4.7 \pm 1.8$ vs. $5.9 \pm 1.7$, $\mathrm{p}=0.044$ ), and in the overall IFS score (mean $38.8 \pm$ 9.6 vs. $47.1 \pm 9.0, p=0.010)$. There was no significant difference between age groups for the financial impact domain (mean $6.0 \pm 2.2$ vs. $6.4 \pm 1.9, \mathrm{p}=0.550$ )

(Figure 2).

The children with working parents or a working single parent $(\mathrm{n}=27)$ demonstrated lower scores (Figure 3), signifying greater impact on family compared to those with a parent at home $(n=19)$ across the general impact domain (mean $23.5 \pm 5$ vs. $27.0 \pm 5.8, p=0.040$ ), the disruption of family domain (mean $19.4 \pm 4.5$ vs. $22.4 \pm$ $4.6, \mathrm{p}=0.033$ ), the coping domain (mean $5.1 \pm 1.4$ vs. 6.3 vs. $1.8, \mathrm{p}=0.028$ ), the financial impact domain (mean 5.8 \pm 2.3 vs. $7.0 \pm 1.3, p=0.037$ ), and the overall IFS score $(42.4 \pm 9.4$ vs. $48.4 \pm 9.0, \mathrm{p}=0.036)$.

There were no significant differences $(p>0.05)$ in overall IFS score, the general impact domain, the disruption of family domain, the coping domain, or the financial impact domain based on patient sex (male or female), within the 4 year and younger age group, and between working parents versus a single working parent.

\section{Feetham Family Functioning Score}

The mean overall FFFS discrepancy score was 20.9 and was normally distributed $(\mathrm{SD}=18.0$; range, $0-79$, Kolmogorov-Smirnov $\mathrm{p}>0.05$ ).

The school-aged children 5-6 years old $(n=12)$ had significantly higher FFFS discrepancy scores than the children 4 years old and younger $(n=34)$, signifying a

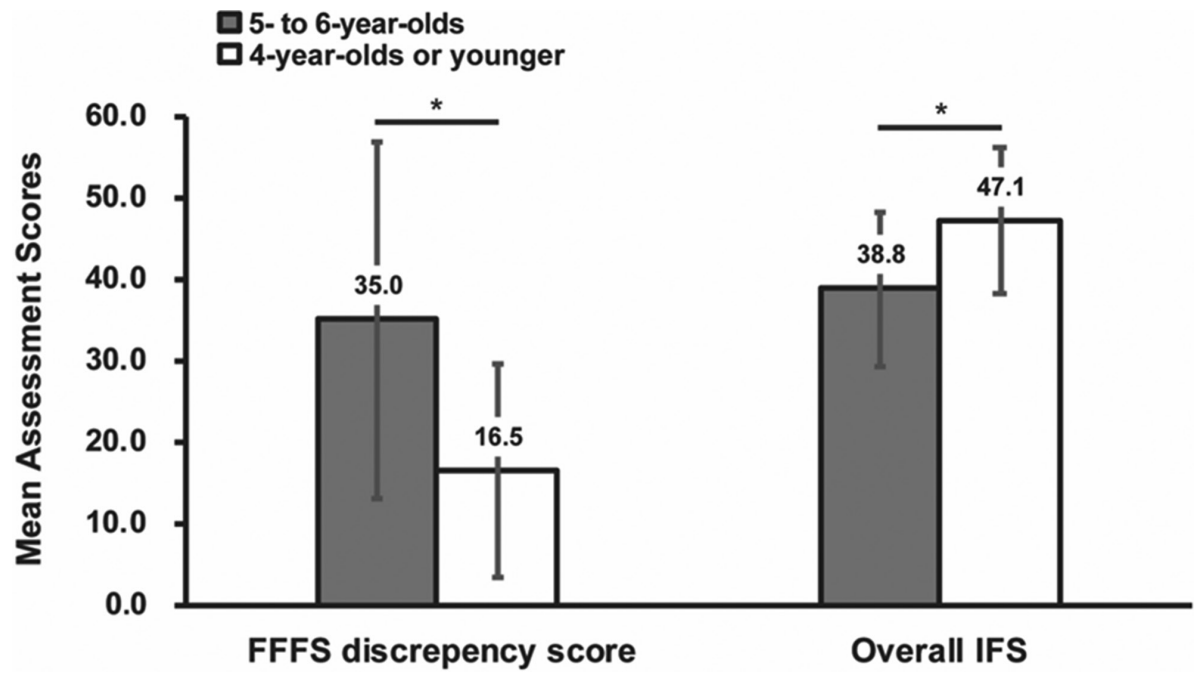

Figure 2. Mean Feetham Family Functioning Survey (FFFS) discrepancy score and Impact-on-Family Scale (IFS) score ( \pm SD) by age group. Mean overall FFFS discrepancy score in 5- to 6-year-old patients is significantly higher than in 4-yearold and younger patients ( $p=0.020)$; mean overall IFS score is significantly higher in 4-year-old and younger patients $(p=0.010)$. Higher FFFS discrepancy scores indicate greater dysfunction in family functioning. Higher IFS scores indicate a lower impact on the family (student t-test ${ }^{*} p<0.05$ ). 


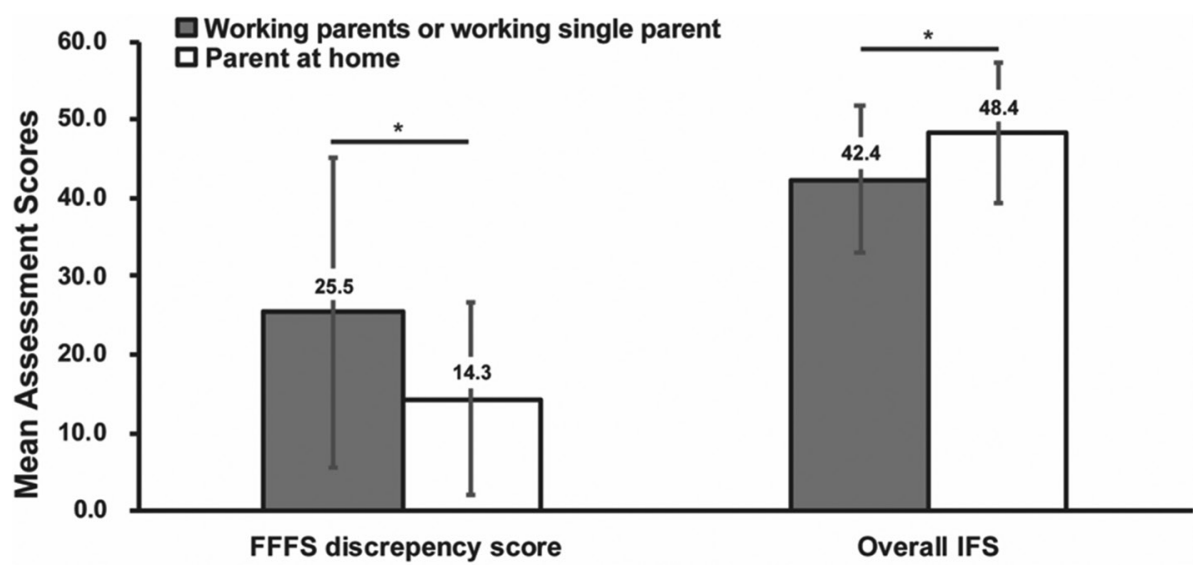

Figure 3. Mean Feetham Family Functioning Survey (FFFS) discrepancy score and Impact-on-Family Scale (IFS) score ( \pm SD) by parent working status. Mean overall FFFS discrepancy score in children with working parents or a working single parent is significantly higher than in children with a parent at home ( $p=0.026)$; mean overall IFS score is significantly higher in children with a parent at home ( $p=0.036)$. Higher FFFS discrepancy scores indicate greater dysfunction in family functioning. Higher IFS scores indicate a lower impact on the family (student t-test $*_{p}<0.05$ ).

greater impact of spica casting on families (mean $35.0 \pm$ 22.2 vs. mean $16.5 \pm 13.2, \mathrm{p}=0.020$ ) (Figure 2 ).

The children with working parents or a working single parent $(n=27)$ demonstrated significantly higher FFFS discrepancy scores than children with a parent at home $(n=19)$, signifying a greater impact of spica casting on the family (mean $25.5 \pm 19.8$ vs. $14.3 \pm 12.3$, $\mathrm{p}=0.026$ ) (Figure 3).

There were no significant differences $(\mathrm{p}>0.05)$ in FFFS discrepancy scores by patient sex (male vs. female), within the 4 year and younger age group, and between working parents versus a single working parent.

Additionally, there was no significant relationship between spica cast duration and FFFS score (Spearman correlation, $\mathrm{r}=-0.111, \mathrm{p}=0.430$ ).

\section{Qualitative Comments}

The qualitative comments demonstrated disparity with some families being able to cope well with spica cast treatment and other families demonstrating difficulty with coping with spica cast treatment. Examples of comments included the following:
- "The spica cast, once we became comfortable with it, made it easy to cater to and transport our son during his injury. After the first week, when he and we were gingerly moving him around, we and he became confident that he was not going to be re-injured by this movement and we were able to resume most our normal activities. My son and I had hockey season tickets and missed only one game out of 10 that were played during his injury."

- “The spica cast was deeply traumatic for my young child and for our entire family. If there is any other treatment option available, it should be used as often as possible. Also, medical personnel should be sensitive to the amount of emotional stress this treatment causes. The idea that a child immobilized is routine, is both ridiculous and demoralizing."

- "I think it would be very helpful for parents to receive a brochure or list of tips \& tricks from us who have been-there-done-that. There are a lot of little tips that I had to Figure out on my own and later spoke with other parents who had discovered the same tricks. 
There are a lot of little things that could be really helpful to these parents."

- "No one prepared us for the 2 weeks of depression he experienced right after he was released from the hospital. His personality totally changed from fun loving and mischievous to very serious and cautious. In all honestly, it was 9 months after the femur break before we had to discipline him for doing anything wrong...now he's back to his old self."

- "Our son ended up with a gastrointestinal virus so this, combined with the normal difficulties of being in a spica cast, made him extremely irritable and sick. My husband and I were very fortunate that we were both able to stay out of work for the duration of his treatment with pay. My other children are teenagers, and my mother-in-law lives with us, so we had a lot of help physically and mentally. The extra support at home made a huge difference, and I don't know how we would have made it through the cast treatment without it."

\section{Discussion}

An ecological framework for medical care includes both the technical considerations of treatment and the psychosocial impact of the treatment on the patient. In the management of pediatric patients, it is important to consider the impact of treatment on the entire family unit. We found that spica casting of pediatric femur fractures places a considerable burden on family functioning as measured by the validated IFS and FFFS assessments. This impact is greater than medical treatment for children with serious chronic medical conditions, such as asthma, diabetes, juvenile rheumatoid arthritis, and renal failure. The burden manifests in family dynamics, relationships, finding caregivers, stigmatization, opportunity costs, lost time, economic hardship, worry, fatigue, depression, marital or family strife, and academic performance of the patient and siblings and is most pronounced in families with older, school-aged children (5-6 years old), compared to younger children ( $0.5-4$ years old), and in families without a parent at home.
The ecological impact of early spica cast treatment compared to other potential treatments has been previously assessed. $8,16,18,19,22,23,25-27$ In a study of the impact of early spica casting for femur fractures in 23 children in the domains of family, school, and support, Hughes et al. found that families identified limited child mobility as the greatest source of burden. ${ }^{46}$ Specifically, families with two working parents needed 3 weeks of time off work on average, as none of the children were accepted into school in the spica cast. Home tutoring for a mean of 8 weeks was required, with 48 tutor-hours per child. However, no children permanently fell behind their peers academically. Mean time to independent walking and running was 5 and 25 days, respectively, with these skills returning faster in younger children. Consistent with our findings, Hughes at al. determined that spica cast management was less burdensome on the families of preschool children. ${ }^{46}$

While in the present study, we only assessed family functioning for immediate spica casting with a one-anda-half leg spica cast, family burden has been compared between various treatment methods. Flynn et al. found a mean 7.7 point improvement on IFS (or reduced family burden) when comparing the burden of the traditional double-legged spica cast to a single-leg cast for the treatment of low-energy pediatric femur fractures. ${ }^{47,48}$ However, in a randomized clinical trial of 52 patients aged 2 to 6 years of age with femoral shaft fractures, Leu et al. found no difference in Activities Scale for Kids scores between children treated with a single-leg versus double-leg spica cast. ${ }^{48}$ The primary advantages cited in their study was more comfort in chairs and car seats and less work missed by parents. ${ }^{48}$

In a study of 75 children treated with either early spica casting $(\mathrm{N}=39)$ or flexible intramedullary nailing $(\mathrm{N}=36)$ for femur fractures in patients aged 2 to 6 years old, Gordon et al. demonstrated comparable clinical outcomes in the two cohorts (e.g., rates of malunion, shortening greater than $2.0 \mathrm{~cm}$ ) and no significant difference in immediate postoperative pain medication use; however, the mean IFS for the spica group was significantly higher 
than that of the nailing group, suggesting less family burden with intramedullary nailing. ${ }^{49}$ Of note, their study included high-energy fractures, which were excluded in the present study. This difference in patient population may explain the significantly lower mean IFS in our study compared to those in the aforementioned spica group (70.2 \pm 7.9 vs. $44.8 \pm 9.3, \mathrm{p}<0.001)$. Therefore, the fracture mechanism is an important consideration when determining the optimal management for pediatric femur fractures in terms of clinical outcomes and family burden.

Other comparative studies of flexible intramedullary nailing versus spica casting for pediatric femur fractures in preschool/school-aged children have demonstrated shorter hospitalization, earlier mobilization, earlier independent bathroom use, earlier return to school, and increased parent satisfaction in patients treated with flexible intramedullary nailing. ${ }^{4,25-27,50-52}$ However, flexible intramedullary nailing increased the risk of knee stiffness, infection, and hardware failure. ${ }^{25-27,52}$ As such, the benefits of avoiding a spica cast via operative treatment in this age group should be balanced against the risks of surgical treatment (e.g., bleeding, infection, nonunion, hardware complications, additional surgery to remove hardware). Subsequent studies of optimizing management of pediatric femur fractures to minimize family burden are necessary to better understand the clinical circumstances when one treatment method is more appropriate than the others.

Despite the greater impact of spica casting on family functioning in older children and those with working parents, the impact on individual families reflected in the qualitative comments was variable. To some families, spica casting was not particularly burdensome and was easily managed within the framework of their existing family routine. In other families, spica casting was tremendously burdensome. We advocate a process of frank discussion and shared decision-making with families to determine the optimal treatment for their child's femur fracture. Caregivers should discuss the potential impact of treatment on family functioning.
In some families, particularly those with school age children and working parents, alternative treatments may be favored. In other families with younger children, a parent at home, or who are surgical risk-adverse, spica casting may be well accepted.

The qualitative comments from families also emphasize the need for improved teaching and family preparation for spica cast treatment. In this study, there was no formalized standard educational program for families treated with a spica cast at our institution during the study period. Development of a formalized educational program involving nursing or social work may have better prepared the families for spica cast treatment and potentially decreased the overall negative impact of treatment on the family. In addition, assistance with obtaining special equipment, managing the patient in school, home healthcare, and a resource contact for follow-up questions would likely have been beneficial. Support groups of parents who have been through spica casting may also be helpful.

\section{Limitations}

Limitations of this study include the qualitative nature of studying impact on family and family functioning. We attempted to optimize the validity of our findings by utilizing previously validated instruments (IFS and FFFS) for the measurement of these domains. While these instruments have not been widely utilized within pediatric orthopaedics, they have been used in the study of other pediatric medical conditions. ${ }^{38,40,41,44}$ Nonetheless, it is difficult to determine whether the family was impacted by the physical spica cast itself, the injury itself, or a combination of both. Another limitation given the retrospective nature of questionnaire distribution is potential response bias in the families who completed the questionnaires; however, we believe that this is limited given the excellent response rate among eligible patients (78\%) observed. Lastly, as discussed earlier, this study only assessed the impact of one-and-ahalf leg hip spica casting on family functioning. Larger comparative studies will be important to better clarify the differences in clinical outcomes and family burden 
of immediate hip spica casting, flexible intramedullary nailing, and submuscular plating in various clinical circumstances (e.g., high-energy versus low-energy femoral shaft fractures).

In conclusion, pediatric femur fracture and spica cast treatment have a major impact on family functioning, particularly in school age children and in families with working parents. Healthcare professionals should consider the impact of treatment on family functioning and recognize that each patient and family unit require education and varying levels of support. Education to families of children undergoing spica cast treatment may help prepare them for the various ways their household dynamics could be affected throughout their child's treatment.

\section{References}

1. Loder RT, O'Donnell PW, Feinberg JR. Epidemiology and mechanisms of femur fractures in children. J Pediatr Orthop. 2006;26(5):561-566.

2. Brousil J, Hunter JB. Femoral fractures in children. Curr Opin Pediatr. 2013;25(1):52-57.

3. Anglen JO, Choi L. Treatment options in pediatric femoral shaft fractures. J Orthop Trauma. 2005;19(10):724-733.

4. Bopst L, Reinberg O, Lutz N. Femur fracture in preschool children: experience with flexible intramedullary nailing in 72 children. $J$ Pediatr Orthop. 2007;27(3):299-303.

5. Buckley SL. Current trends in the treatment of femoral shaft fractures in children and adolescents. Clin Orthop Relat Res. 1997;(338):60-73.

6. Czertak DJ, Hennrikus WL. The treatment of pediatric femur fractures with early 90-90 spica casting. J Pediatr Orthop. 1999;19(2):229-232.

7. Ferguson J, Nicol RO. Early spica treatment of pediatric femoral shaft fractures. J Pediatr Orthop. 2000;20(2):189-192.

8. Flynn JM, Schwend RM. Management of pediatric femoral shaft fractures. J Am Acad Orthop Surg. 2004;12(5):347-359.

9. Gardner MJ, Lawrence BD, Griffith MH. Surgical treatment of pediatric femoral shaft fractures. Curr Opin Pediatr. 2004;16(1):51-57.

10. Hunter JB. Femoral shaft fractures in children. Injury. 2005;36(Suppl 1): A86-A93.

11. Kanlic E, Cruz M. Current concepts in pediatric femur fracture treatment. Orthopedics. 2007;30(12):1015-1019.

12. Sponseller PD. Surgical management of pediatric femoral fractures. Instr Course Lect. 2002;51:361-365.

13. Wright JG. The treatment of femoral shaft fractures in children: a systematic overview and critical appraisal of the literature. Can J Surg. 2000;43(3):180-189.

14. Jevsevar DS, Shea KG, Murray JN, et al. AAOS clinical practice guideline on the treatment of pediatric diaphyseal femur fractures. $J \mathrm{Am}$ Acad Orthop Surg. 2015;23(12):e101.

15. Rickert KD, Hosseinzadeh P, Edmonds EW. What's new in pediatric orthopaedic trauma: the lower extremity. J Pediatr Orthop. 2018;38(8):e434-e439.

16. Casas J, Gonzalez-Moran G, Albiñana J. Femoral fractures in children from 4 years to 10 years: conservative treatment. $J$ Pediatr Orthop B. 2001;10(1):56-62.
17. Cassinelli EH, Young B, Vogt M, et al. Spica cast application in the emergency room for select pediatric femur fractures. J Orthop Trauma. 2005;19(10):709-716.

18. Epps HR, Molenaar E, O’Connor D P. Immediate single-leg spica cast for pediatric femoral diaphysis fractures. J Pediatr Orthop. 2006;26(4):491-496.

19. Frech-Dörfler M, Hasler CC, Häcker FM. Immediate hip spica for unstable femoral shaft fractures in preschool children: still an efficient and effective option. Eur J Pediatr Surg. 2010;20(1):18-23.

20. Henderson OL, Morrissy RT, Gerdes MH, et al. Early casting of femoral shaft fractures in children. J Pediatr Orthop. 1984;4(1):16-21.

21. Illgen R, 2nd, Rodgers WB, Hresko MT, et al. Femur fractures in children: treatment with early sitting spica casting. J Pediatr Orthop. 1998;18(4):481-487.

22. Infante AF, Jr., Albert MC, Jennings WB, et al. Immediate hip spica casting for femur fractures in pediatric patients. A review of 175 patients. Clin Orthop Relat Res. 2000(376):106-112.

23. Wilson NC, Stott NS. Paediatric femoral fractures: factors influencing length of stay and readmission rate. Injury. 2007;38(8):931-936.

24. Yandow SM, Archibeck MJ, Stevens PM, et al. Femoral-shaft fractures in children: a comparison of immediate casting and traction. $J$ Pediatr Orthop. 1999;19(1):55-59.

25. Greisberg J, Bliss MJ, Eberson CP, et al. Social and economic benefits of flexible intramedullary nails in the treatment of pediatric femoral shaft fractures. Orthopedics. 2002;25(10):1067-1070; discussion 1070.

26. Jauquier N, Doerfler M, Haecker FM, et al. Immediate hip spica is as effective as, but more efficient than, flexible intramedullary nailing for femoral shaft fractures in pre-school children. J Child Orthop. 2010;4(5):461-465.

27. Shemshaki HR, Mousavi H, Salehi G, et al. Titanium elastic nailing versus hip spica cast in treatment of femoral-shaft fractures in children. J Orthop Traumatol. 2011;12(1):45-48.

28. Creer TL, Stein RE, Rappaport L, et al. Behavioral consequences of illness: childhood asthma as a model. Pediatrics. 1992;90(5 Pt 2):808-815

29. Jessop DJ, Riessman CK, Stein RE. Chronic childhood illness and maternal mental health. J Dev Behav Pediatr. 1988;9(3):147-156.

30. Newacheck PW, Stein RE, Walker DK, et al. Monitoring and evaluating managed care for children with chronic illnesses and disabilities. Pediatrics. 1996;98(5):952-958.

31. Stein RE, Jessop DJ. Measuring health variables among Hispanic and non-Hispanic children with chronic conditions. Public Health Rep. 1989;104(4):377-384.

32. Stein RE, Zitner LE, Jensen PS. Interventions for adolescent depression in primary care. Pediatrics. 2006;118(2):669-682.

33. Stein RI, Epstein LH, Raynor HA, et al. The influence of parenting change on pediatric weight control. Obes Res. 2005;13(10):1749-1755.

34. Stein RE, Jessop DJ. Does pediatric home care make a difference for children with chronic illness? Findings from the Pediatric Ambulatory Care Treatment Study. Pediatrics. 1984;73(6):845-853.

35. Stein RE, Jessop DJ. The impact on family scale revisited: further psychometric data. J Dev Behav Pediatr. 2003;24(1):9-16.

36. Stein RE, Riessman CK. The development of an impact-on-family scale: preliminary findings. Med Care. 1980;18(4):465-472.

37. Roberts CS, Feetham SL. Assessing family functioning across three areas of relationships. Nurs Res. 1982;31(4):231-235.

38. Jones EG. Deaf and hearing parents' perceptions of family functioning. Nurs Res. 1995;44(2):102-105.

39. Sawyer EH. Family functioning when children have cystic fibrosis. $J$ Pediatr Nurs. 1992;7(5):304-311.

40. Starzomski R, Hilton A. Patient and family adjustment to kidney transplantation with and without an interim period of dialysis. Nephrol Nurs J. 2000;27(1):17-18, 21-32; discussion 33, 52. 
41. Youngblut JM, Lauzon S. Family functioning following pediatric intensive care unit hospitalization. Issues Compr Pediatr Nurs. 1995;18(1):11-25.

42. Youngblut JM, Shiao SY. Child and family reactions during and after pediatric ICU hospitalization: a pilot study. Heart Lung. 1993;22(1):46-54

43. Youngblut JM, Singer LT, Madigan EA, et al. Maternal employment and parent-child relationships in single-parent families of low-birth-weight preschoolers. Nurs Res. 1998;47(2):114-121.

44. Connelly TW, Jr. Family functioning and hope in children with juvenile rheumatoid arthritis. MCN Am J Matern Child Nurs. 2005;30(4):245-250.

45. Yantzi N, Rosenberg MW, Burke SO, et al. The impacts of distance to hospital on families with a child with a chronic condition. Soc Sci Med. 2001;52(12):1777-1791.

46. Hughes BF, Sponseller PD, Thompson JD. Pediatric femur fractures: effects of spica cast treatment on family and community. J Pediatr Orthop. 1995;15(4):457-460.

47. Flynn JM, Garner MR, Jones KJ, et al. The treatment of lowenergy femoral shaft fractures: a prospective study comparing the "walking spica" with the traditional spica cast. J Bone Joint Surg Am. 2011;93(23):2196-2202.

48. Leu D, Sargent MC, Ain MC, et al. Spica casting for pediatric femoral fractures: a prospective, randomized controlled study of single-leg versus double-leg spica casts. J Bone Joint Surg Am. 2012;94(14):1259-1264.

49. Gordon JE, Anderson JT, Schoenecker PL, et al. Treatment of femoral fractures in children aged two to six. Bone Joint J. 2020;102-B(8):1056-1061.

50. Mortier D, De Ridder K. Flexible intramedullary nailing in the treatment of diaphyseal fractures of the femur in preschool children. Acta Orthop Belg. 2008;74(2):190-194

51. Simanovsky N, Porat S, Simanovsky N, et al. Close reduction and intramedullary flexible titanium nails fixation of femoral shaft fractures in children under 5 years of age. J Pediatr Orthop B. 2006;15(4):293-297.

52. Flynn JM, Luedtke LM, Ganley TJ, et al. Comparison of titanium elastic nails with traction and a spica cast to treat femoral fractures in children. $J$ Bone Joint Surg Am. 2004;86(4):770-777. 